\title{
Job Satisfaction of Academics: Does Gender Matter?
}

\author{
Maria de Lourdes Machado-Taylor ${ }^{\mathrm{a}}$, Kate White $^{\mathrm{b}}$ and \\ Odilia Gouveia ${ }^{\mathrm{c}, \mathrm{d}}$ \\ ${ }^{\mathrm{a} C}$ CIPES-Center for Research in Higher Education Policies. \\ E-mail:1machado@cipes.up.pt \\ ${ }^{\mathrm{b}}$ Federation University, Australia. \\ E-mail: kate.white@ federation.edu.au \\ ${ }^{\mathrm{c}} \mathrm{PhD}$ Student in Sociology in University of Minho. \\ ${ }^{\mathrm{d}}$ Researcher at the Center for Research on Higher Education Policies (CIPES). \\ E-mail: gouveia.odilia@gmail.com
}

\begin{abstract}
Academic work in higher education has been influenced by global trends such as accountability, massification and deteriorating financial support. Within this broader context, the performance of academic staff as teachers and researchers has an impact on student learning and implications for the quality of higher education institutions (HEIs). Therefore, satisfaction of academic staff is critical to the effective functioning of HEIs. This article reports on a study of academic career satisfaction in Portugal and gender differences with respect to academic job satisfaction. It found that male respondents in HEIs were in higher positions than women, but less so in private institutions. It also analysed some aspects of the professional context in which women and men work in order to explain similarities and/or differences in job satisfaction. The main difference was that women were less satisfied with personal and professional development, especially the balance between work and family.

Higher Education Policy (2014) 27, 363-384. doi:10.1057/hep.2013.34;

published online 5 November 2013; corrected online 18 March 2014
\end{abstract}

Keywords: job satisfaction; academic staff; gender; higher education

\section{Introduction}

Academic staff are a key resource within higher education institutions (HEIs) and therefore have a major role in achieving their objectives. The importance of academics and their job satisfaction in academia is self-evident (Hagedorn, 1995; Machado-Taylor et al., 2011), given that their performance as teachers and researchers determines much of the quality of student satisfaction and has an impact on student learning and thus the contribution of HEIs to society (Hagedorn, 1995; Machado-Taylor et al., 2010).

Although there have been numerous studies of job satisfaction, there has been relatively little empirical data gathered on job satisfaction of university teachers, 
and even less on significant gender differences (Okpara et al., 2005). According to Bimrose $(2001,2004)$, there are gender differences in the labour market that are being neglected. There are still cultural, political, organizational and social obstacles that prevent female academics from reaching their full potential and being satisfied with their jobs. These include horizontal and vertical segregation (CIREM, 2007), as discussed later.

While gender in this study is mainly conceptualized as a demographic variable, it is recognized that the interplay between women academics and HEIs is much more complex. As Ely and Padavic (2007, 1138-1139) assert, 'organisations serve as historically situated contextual constraints within which people are capable of exercising choice. The interplay between organisations and individuals shapes and reshapes, creates and recreates gender identities in potentially infinite ways'. Such an approach 'represents a radical reframing of both gender identity and the role organisations play in constructing it'.

The study of gender differences in the job satisfaction of academics is important. It can provide institutional leaders with information that will enable them to recruit and retain faculty, improve the happiness of academic staff, improve organizational commitment and decrease turnover and absenteeism (Gazioglu and Tansel, 2006). Other authors such as Hagedorn (1995) emphasize the importance and the relevance of research on job satisfaction of female academics who are under-represented at more senior levels and typically have lower status positions.

There are several studies on gender differences in academic job satisfaction. Oshagbemi (2000) found that gender did not affect job satisfaction of university teachers directly; however, the interaction of gender and rank was statistically significant. Overall, female academics at higher ranks (senior lecturers, readers and professors) expressed more satisfaction with their jobs than male academics of comparable rank. August and Waltman (2004) argued that retention of female faculty is critical for HEIs aiming for excellence and diversity, and that a crucial first step in understanding retention is to study what contributes to career satisfaction for academic women. Meanwhile, Bilimoria et al. (2006) found that men tend to achieve more satisfaction with academic work than women through greater availability of internal academic resources, while women tend to derive greater satisfaction than men from academic work where there is an inclusive work environment characterized by respect and appreciation of the contribution of all staff.

The impact of gender differences on the job satisfaction of academics in the United States was examined by Okpara et al. (2005). They found that female faculty were more satisfied with their work and co-workers, while male faculty were more satisfied with their pay, promotions, supervision and overall job satisfaction. In another US study, Bender and Heywood (2006) estimated the determinants of job satisfaction for Ph.D. level scientists across academic and non-academic sectors. They found that female scientists show lower job satisfaction than males in academia, but higher job satisfaction than males in the non-academic sector. In addition, 
academic scientists with tenure had considerably greater job satisfaction than nonacademic scientists, but academic scientists without tenure reported comparable levels of satisfaction with non-academic scientists.

Several other studies concluded that male faculty earn more money than female faculty, and female faculty tend to be concentrated in the lower ranks and are more involved in part-time teaching (Okpara et al., 2005).

Therefore the literature suggests that while women in higher education have made considerable progress, there are still cultural, political, organizational and social obstacles that prevent them from reaching their full potential. In addition, women have different and often more complex career paths than men. Major influences on women's career decisions appear to come from 'care responsibilities', such as childbirth and child care, sharing roles and responsibilities with a partner in a 'dualearner' family or caring for ageing parents (Bartosz et al., 2006).

This article explores the gender and academic/professional context, and then identifies differences between male and female academics in Portuguese higher education, using publicly available statistics. Finally, it analyses the results of a nation-wide study of satisfaction with academic careers in Portuguese higher education and draws some preliminary conclusions.

\section{Gender and Professional Context}

Gender inequalities persist in most professional fields. Several studies have analysed the difficulties women face in career progression. While the Eurydice Network $(2009,4)$ found that 'around two thirds of countries have gender equality policies in higher education', horizontal gender segregation — women and men being concentrated in certain disciplines or institutional sectors - remains. For example, women are underrepresented in science, especially in engineering and physical sciences (CIREM, 2007). The OECD (2006) identified several factors that contribute to horizontal segregation.

Individual factors include women making a choice to pursue a career in a certain field and gender stereotypes can affect the direction of these choices. Interpersonal factors are the type of networks in which women may be involved or a lack of networking that can impact on the decision to seek careers in certain scientific fields. Organizational structures are an additional factor. The structure of the workplace (e.g., hierarchical), recruitment and promotion practices, and workplace culture can influence the career paths of women. A further factor is societal attitudes; gender stereotypes can affect the choices girls and women are more or less encouraged to make in pursuing scientific careers. A final factor is sex discrimination that includes discrimination having a material impact (e.g., denial of jobs or tenure) and perceived discrimination that discourages women.

Significant patterns of horizontal segregation were found, for example, with regard to the participation of women by scientific field and institutional 
sector. Interestingly, Portugal has a relatively high proportion of researchers in the higher education sector compared with other European countries; the percentage of female researchers in Portugal is 45.9, compared with Denmark (33.5), Finland (42.9), Germany (25.0), Norway (37.6), Sweden (43.7) and is above the EU 25 (34.0) (European Union (EU), 2010). This high representation of women researchers in Portugal reflects the high percentage of women as academics in higher education when compared with other European countries (Carvalho, 2012).

Vertical gender segregation refers to the unequal position of women and men, especially within scientific hierarchies. The persistence of the 'glass ceiling' or 'sticky floor' for women seeking to progress to senior positions is evident in all occupational sectors, even those that are dominated by women (CIREM, 2007). The absence of women in leadership positions is more pronounced in science and technology than in other areas (cited in CIREM, 2007). Such structural barriers systematically exclude women from developing their careers in academia. UK research found that 'although the picture is slowly improving, women make up $42.6 \%$ of the overall academic staff population, but a much lower proportion $(18.7 \%)$ are at head of school or professorial level' (Barrett and Barrett, 2011, 141). Possible explanations of the gender gap, according to Hagedorn (1995, 8-9) are that '[...] married women have frequently curtailed their career mobility in favor of their husbands' career advancement. [...] [which] has been voluntary due to personal constraints [...]' and that some forms of mobility are highly gendered and 'present unique challenges to people with personal and caring responsibilities' (Ackers, 2010, 83).

In the EU, women constitute the majority of students and graduates in almost all countries and dominate in education, health and welfare, humanities and the arts, whereas men dominate in construction, manufacturing and engineering (EU, 2010).

Approximately two-thirds of European countries have gender equality policies in higher education, but almost all these policies only target women. However, in Portugal there are no gender equality policies in higher education.

According to the EU (2010), the representation of women as teaching staff in HEIs declines with every step on the academic career ladder. Nevertheless, only about a third of the countries have implemented policies to address this problem by targeting vertical segregation. Cabrera (2009) argues that as the need to compete for talent increases, organizations are failing to retain highly educated women. While men and women are entering the workforce at the same rate, their numbers are increasingly disproportionate as they move up the organizational hierarchy.

The evolution of the gender gap during the stages of an academic career in EU 25 countries, beginning with enrolment at the basic level of higher education (bachelor and master graduates, ISCED 5A) through to the highest academic position (academic staff Grade A, equivalent to full professor) has been documented (European Commission, 2006). In 2003, women accounted for 59\% of bachelor and master graduates, but no more than $15 \%$ of full professors (CIREM, 2007). 
Moreover, the position of women had not significantly improved between 1999 and 2003.

The proportion of women professors, although consistently low, varies significantly across EU countries, from above $20 \%$ in Portugal, Romania, Turkey and Finland, to below $10 \%$ in Austria, the Netherlands, Germany, Belgium and Malta. Therefore, it has been argued that HEIs need to pay more attention to policies and practices that persist in discriminating against women, particularly at senior levels in academia (White et al., 2010).

In this context, equal opportunities policies play a vital role, which implies a change in attitudes and behaviour leading to considerable changes in work organization, working conditions and the working environment (Commission of the European Communities, 1993). Promoting equal opportunities is important because:

Quality in education depends in large part on the quality of the teaching staff. Gender balance among the staff is critical for promoting gender parity and equality in access to, and achievement in, education and for creating a supportive and non-discriminating learning environment for both women and men.(United Nations, 2010, 65)

Some authors recognize the urgency of gender mainstreaming, described as 'the (re)organisation, improvement, development and evaluation of policy processes, so that a gender equality perspective is incorporated in all policies, at all levels and at all stages, by the actors normally involved in policymaking' (Kuperus et al., 2008, 56). Thus with gender mainstreaming, a gender equality perspective is taken into account at all levels in all policy fields.

\section{Academics in Portuguese Higher Education — Differences between Female and Male Academics}

The proportion of female academics $(15,364 ; 43.4 \%)$ is lower than the proportion of male academics in higher education $(20,016 ; 56.6 \%)$. Analysing by type of institution, we can see in Figure 1 that there are lower proportions of women than men in public higher education (universities and polytechnics). By contrast, in private higher education, the number of women in polytechnics is higher than the number of men (2,192 and 1,941, respectively).

Figure 2 shows the distribution of academic staff by age group and sex in 2008; the age groups with high proportions of academics (men and women) are 30-39 and $40-49$. The age groups with fewer academics are $<30$ and 60 or more years. In the age groups $40-49,50-59$ and 60 or more years, the number of men is higher than the number of women. With respect to academics aged less than 40 years, the gender difference is not significant. 
if. Maria de Lourdes Machado-Taylor et al

368

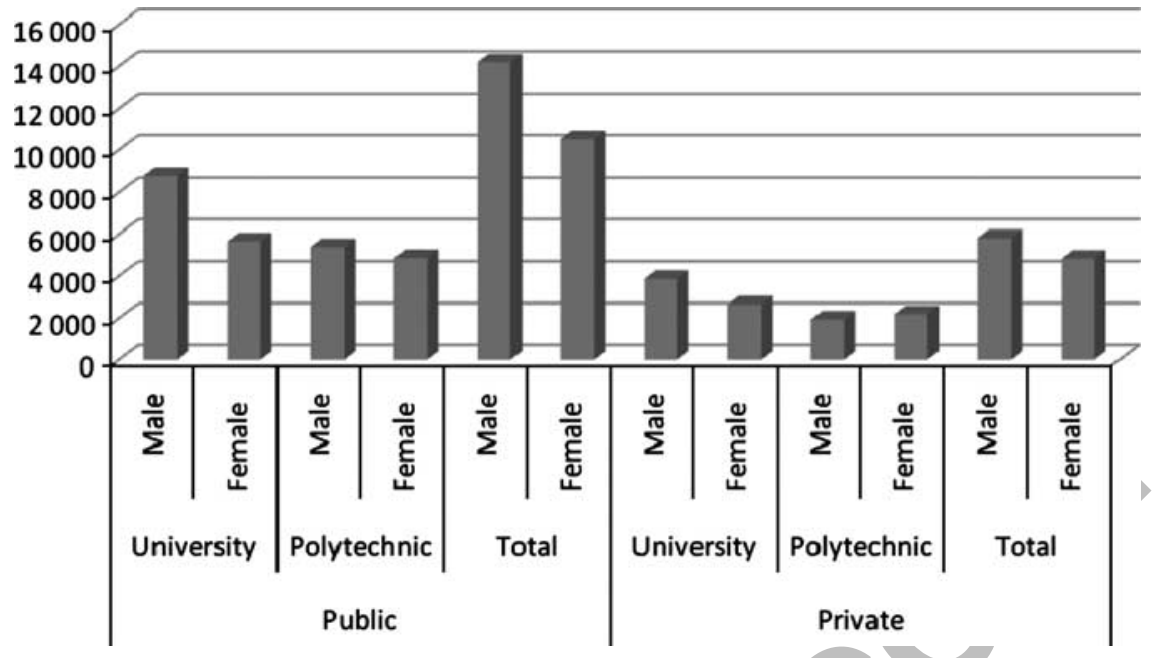

Figure 1. Academics by type of education and sex in 2008 in Portugal. Source: GPEARI (2010) Docentes do Ensino Superior [2001 a 2008], Lisbon: Gabinete de Planeamento, Estratégia, Avaliação e Relações Internacionais.

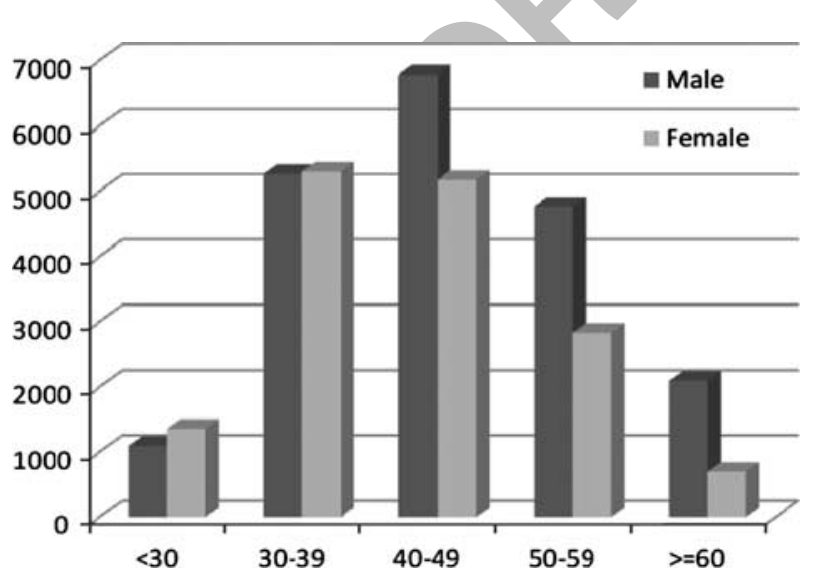

Figure 2. Academics by age group and sex in 2008 in Portugal.

Source: GPEARI (2010) Docentes do Ensino Superior [2001 a 2008], Lisbon: Gabinete de Planeamento, Estratégia, Avaliação e Relações Internacionais.

The distribution of academics by highest academic degree (Figure 3) indicates significant proportions of academics with the degree 'Doctor' $(14,205 ; 40.1 \%)$, following this degree the degree Licenciado $(11,217 ; 31.7 \%)$ and 'Master' $(9,472$; 


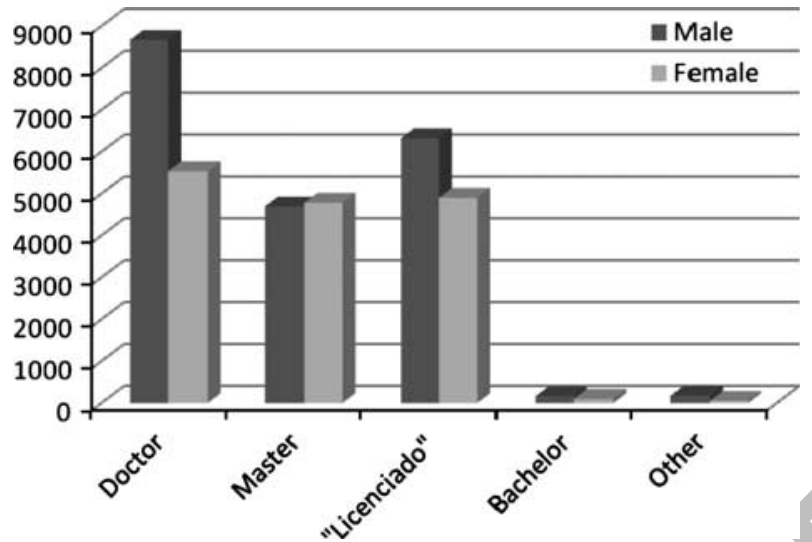

Figure 3. Academics by highest academic degree and sex in 2008 in Portugal. Source: GPEARI (2010) Docentes do Ensino Superior [2001 a 2008], Lisbon: Gabinete de Planeamento, Estratégia, Avaliação e Relações Internacionais.

26.8\%). There are more academic men than women with the degrees 'Doctor', Licenciado, 'Bachelor' and 'Other', whereas more women than men have a Masters degree (4,780 and 4,692 academics, respectively).

The distribution of academic staff by area of education and sex in 2008 show considerable differences between the disciplines. Higher proportions are from 'Social Sciences, Commerce and Law' $(8,510 ; 24.6 \%)$, 'Engineering, Manufacturing Industries and Construction' $(6,384 ; 18 \%)$ and 'Science, Mathematics and Computer' $(5,305 ; 15 \%)$. The proportion of professors in 'General Programs' $(23 ; 0.06 \%)$, 'Agriculture' (890; $2.5 \%)$ and 'Services' $(1,570 ; 4.4 \%)$ is much lower. With respect to gender differences, there are higher proportions of men than women in almost all disciplines, except in 'Health and Social Protection' and 'Education'. The largest gender difference is in 'Engineering, Manufacturing Industries and Construction' (76.2\% men and $23.8 \%$ women).

In public university higher education in Portugal (Figure 4), the highest proportion of academics are 'Assistant Professor' (6,452; 44.6\%), 'Assistant' (3,590; 24.8\%) and 'Associate Professor' $(2,274 ; 15.7 \%)$. At each level, there are more men than women, except for 'Reader'. The most significant differences between men and women are at 'Full Professor' and 'Associate Professor' level where there are higher proportions of men than women.

In public polytechnic higher education, the highest proportion of academics are 'Adjunct Professor' $(4,069 ; 39.7 \%)$, 'Assistant $2^{\circ}$ triennium' $(2,265 ; 22.1 \%)$ and 'Assistant $1^{\circ}$ triennium' $(1,612 ; 15.7 \%)$. There are more men than women at the more senior levels of 'Adjunct Professor' and 'Coordinator Professor'. In contrast, there 


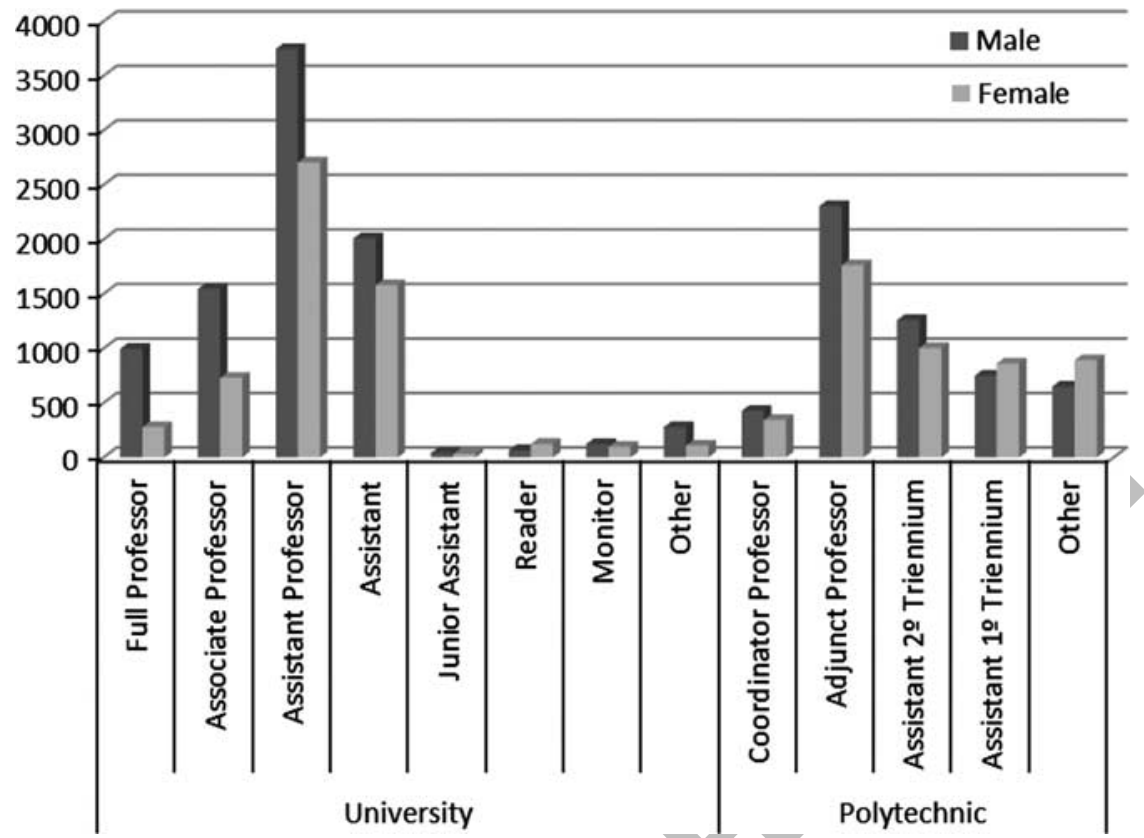

Figure 4. Academics in public higher education by academic position and sex in 2008 in Portugal. Source: GPEARI (2010) Docentes do Ensino Superior [2001 a 2008], Lisbon: Gabinete de Planeamento, Estratégia, Avaliação e Relações Internacionais.

are more women than men in the lower academic positions 'Assistant $1^{\circ}$ triennium' and 'Other', reflecting the global trend of women being concentrated at lower academic levels.

In private universities (Figure 5), the highest proportion of academics are 'Assistant' (2,687; 41.2\%); 'Assistant Professor' (1,692; 26\%) and 'Junior Assistant' $(745 ; 11.4 \%)$, and in each of these levels there are more men than women. The biggest gender differences are in the top academic positions - 'Full Professor' and 'Associate Professor' - where there is a much higher representation of men.

In private polytechnics, the highest proportions of academics are 'Assistant $2^{\circ}$ triennium' $(2,064 ; 49.9 \%)$ and 'Adjunct Professor' $(977 ; 23.6 \%)$. There are more men than women in the position of 'Coordinator Professor'. Thus, the difference in representation of men and women in private polytechnics is less significant when compared with private universities, public universities and public polytechnics. This situation is probably due to the lower status of private polytechnics (Reskin and Roos, 1990; Reskin and Bielby, 2005), and therefore those jobs are less preferred by men. 


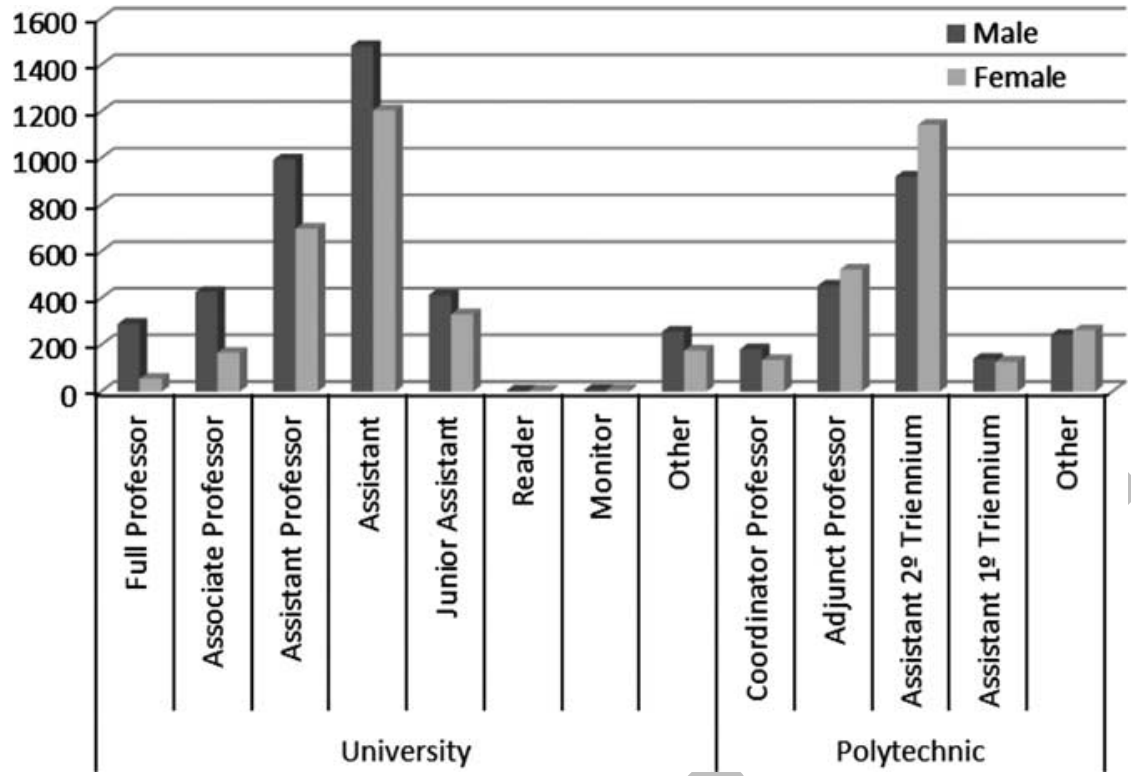

Figure 5. Academics in private higher education by academic position and sex in 2008 in Portugal. Source: GPEARI (2010) Docentes do Ensino Superior [2001 a 2008], Lisbon: Gabinete de Planeamento, Estratégia, Avaliação e Relações Internacionais.

\section{Methodology}

The data presented here is from a nation-wide study funded by the Foundation for Science and Technology' entitled 'An Examination of Academic Job Satisfaction and Motivation in Portuguese Higher Education'. This project was developed in the Center for Research in Higher Education Policies, University of Porto, and involved the application and analysis of the results of a questionnaire.

All academics in Portuguese Higher Education - including all sub-groups (professor, researcher, part-time, full-time) of all institutional type of Portuguese HEIs (public-private, university-polytechnic) - were invited to fill in an online survey. The questionnaire was available to all Portuguese academics on the website: http://questionarios.ua.pt/index.php?sid=19766\&lang=pt that was forwarded to them. A total of 4,529 faculty members participated in the study. The database was analysed using the Statistical Package for the Social Sciences (SPSS). Statistical procedures used in this article included descriptive statistics, custom tables, synthetic indexes created through algebraic transformation $(\bar{x})$ and Principal Component Analysis with a single component. In the social sciences, many different concepts have been measured using multiple indicators, such as media use, political efficacy, 
social trust, political trust, party identification, religiosity, attitudes towards immigrants, human values and fear of crime. In order to develop measures for these concepts, several steps have to be undertaken: (1) The items have to be evaluated on quality and on equivalence across countries, (2) weights have to be chosen for the calculation of the composite scores and (3) the quality of the composite scores has to be determined (Silva, 2011).

The distribution of the respondents by sex was as follows: male 50.7\%; and female $49.3 \%$. There are slightly more men (56.6\%) and slightly less women $(43.4 \%)$ in academia in Portuguese higher education. This indicates that our sample had a higher percentage of female respondents compared with the representation of women in Portuguese higher education. The response rate obtained was of $12.5 \%$, which is much higher than usual for a study of national dimension and administered online. The vast majority of the respondents $(91.9 \%)$ had a partner (husband/wife) that worked. Moreover, $30.3 \%$ of respondents were married to other academics.

The dimensions of satisfaction in this study were chosen after an extensive literature review as well as analysis of questionnaires by experts in the area of academic job satisfaction and motivation. These dimensions were: Teaching Climate; Management of the Institution/Department/Unit; Colleagues; NonAcademic Staff (administrative staff, technical and laboratorial staff); Physical Work Environment; Conditions of Employment; Personal and Professional Development; Institutions' Culture and Values; and Institutions' Prestige and Research Climate. Table A1 in the appendix shows each aspect considered for each of these dimensions.

\section{Survey Results}

\section{Differences in job satisfaction between female and male academics}

\section{General satisfaction/satisfaction dimensions}

Respondents were asked to rate their satisfaction with their jobs, institution, opportunity to update knowledge, adequacy of skills to their teaching practice and social prestige of the job. While they were generally satisfied (mean= 6.30), on a scale from 0 to 10, 'Extremely dissatisfied' to 'Extremely satisfied', their satisfaction was not very high, that is, it was not close to point 10 on the scale.

The 'Custom Tables' in SPSS indicated that general satisfaction of academics was similar for women and men, but that men seemed to be slightly more satisfied (general satisfaction for men was 0.013 and for women the value was 0.006).

Nevertheless, using the test Independent-Samples t-Test, and considering a significance level of 0.05 , we find that the difference between women and men 
was not statistically significant $(t(2998.834)=-0.186 ; p>0.05)$. This result was similar to that of other studies in other countries. For example, Ward and Sloane (2000), Santhapparaj and Alam (2005) and Stevens (2005) found that women expressed similar levels of satisfaction when compared with men.

When asked if they would advise other people to work in their current and primary institution, the majority of the academics responded 'Yes' $(52.9 \%)$, but a significant proportion responded 'No' or 'I don't know' (31\%). However, 16.1\% of the academic staff did not respond to this question.

The data reveals some gender differences with respect to the question of whether or not they would advise other people to work in their current and primary institution. More male than female academics would advise others to teach in their current and primary institution $(51.7 \%$ and $48.3 \%$, respectively). Furthermore, more men than women would not advise other people to work in their institution (54.6\% and 45.4\%, respectively). Nevertheless, more women said 'I don't know' or did not respond. This might suggest that women were more indecisive than men in advising other people to work in their current and primary institution.

Analysing the synthetic indexes for each dimension of satisfaction, we can verify that the higher values are in the dimensions 'Non-Academic Staff (administrative staff, technical and laboratorial staff)' (mean=6.3), 'Teaching Climate' (mean=6.0) and 'Colleagues' (mean=6.0). In contrast, the dimensions in which academics expressed less satisfaction were 'Research Climate' (mean=4.2) and 'Conditions of Employment' (mean= 4.3) (Figure 6).

These results are consistent with Ssesanga and Garrett's (2005) conclusion that academics were relatively satisfied with co-worker behaviour and intrinsic factors of teaching. Ward and Sloane (2000) found that academics were most satisfied with the opportunity to use their own initiative, the relationship with their

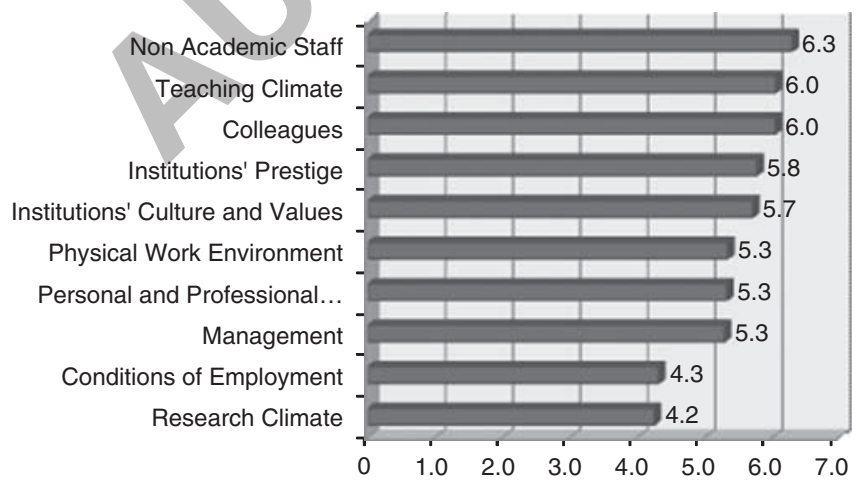

Figure 6. Satisfaction dimensions (synthetic indexes).

Scale: $0=$ Strongly dissatisfied; $10=$ Strongly satisfied. 
colleagues and the actual work, and were least satisfied with promotion prospects and salary. In the present study, academics were least satisfied with conditions of employment and research climate.

Analysing academics' satisfaction in the dimensions 'Non-Academic Staff', 'Physical Work Environment', 'Conditions of Employment' and 'Institutions' Culture and Values' by sex using the Independent-Samples $t$-Test, and considering a significance level of 0.05 , we can verify that the difference between the satisfaction of women and men with these aspects was not statistically significant.

With respect to the dimensions 'Teaching Climate', 'Management', 'Colleagues', 'Personal and Professional Development', 'Institutions' Prestige' and 'Research Climate' and the degree of satisfaction with these aspects, using the same test, we conclude that there were statistically significant differences between men and women. Men (mean=6.1482) were more satisfied than women (mean=6.0121) with 'Teaching Climate'; women (mean=5.4210) were more satisfied than men $(m e a n=5.1321)$ with the dimension 'Management'; women $($ mean=6.1826) were more satisfied than men (mean=5.9532) with 'Colleagues'; men expressed more satisfaction (mean=5.5500) than women $($ mean=5.1712) with 'Personal and Professional Development'; women $($ mean $=5.9437)$ indicated more satisfaction than men (mean=5.6011) with 'Institutions' Prestige'; and finally, men (mean=4.4818) were more satisfied than women (mean=4.0807) with 'Research Climate'.

In short, women were more satisfied than men with management, colleagues and the institution's prestige. In contrast, men were more satisfied than women with teaching and research climate and personal and professional development. A possible explanation is the considerable challenge for women in balancing work and family. HEIs still need to address endemic problems relating to work-life balance, the glass ceiling and the organizational culture (Munn, 2011). Moreover, women need to deal with marriage, having children, returning to the workforce when the children are older and the pattern of repeated 'entrances' and 'departures' from the workforce and, in this context, the challenges of building a 'career' (Bartosz et al., 2006).

\section{Interrelations between career and family - The satisfaction dimension 'personal and professional development'}

The dimension 'Personal and Professional Development' includes the aspects 'conditions you have to balance work and family life', 'conditions you have for your personal development' and 'conditions you have for your professional development'. This dimension is particularly important in the context of an analysis by gender.

Women were slightly less satisfied than men with all aspects of the dimension 'Personal and Professional Development'. With respect to conditions for professional development, the mean of satisfaction for men was 5.4 and for women 5.1. The mean of satisfaction with conditions for personal development was 5.5 for men and 5.1 for women. Finally, the mean of satisfaction with conditions for balancing 
work and family was 5.8 for men and only 5.3 for women. Thus, the most significant difference between men and women related to satisfaction with conditions for achieving a balance between work and family.

If in some western European countries high rates of female employment follow a progressive balance of the status and roles assigned to women and men within the family group, in Portuguese society, despite some advances, there is still quite traditional behaviour in relation to supporting the family. In most cases, the care of children or the elderly and parents is mainly the responsibility of women. It is therefore necessary to rethink the ways of organizing work in order to provide a balance between family and professional responsibilities of workers of both sexes. This is an important theme that has been widely discussed and is enshrined in the Constitution of Portuguese Republic. Guerreiro et al. (2006) suggest some modalities required to promote reconciliation between work and family life, including: establishing care services for children and the elderly; introducing parental leave for working fathers and mothers; encouraging greater participation of the father in family life and flexible work arrangements. To help reconcile work and family responsibilities, some countries and institutions have established shorter work hours and family-friendly working arrangements such as flexible hours, part-time work, job-sharing and working from home (United Nations, 2010).

\section{Differences between female and male academics in the academic/professional context}

In this section, we analysed the gender differences that characterize the academic/ professional context, such as academic position, length of contract and working regime. With respect to academic position (Table 1), in public HEIs males were dominant in higher academic positions such as full professor and associate professor (male full professors $-73.5 \%$; male associate professors $-59.4 \%$ ). Females were

Table 1 Academic position by sex

\begin{tabular}{lrrrrr}
\hline & \multicolumn{2}{c}{ Female } & & \multicolumn{2}{c}{ Male } \\
\cline { 2 - 3 } \cline { 5 - 6 } & Count & Row N\% & & Count & Row N\% \\
\hline Academic position & & & & & \\
Full professor & 35 & 26.5 & & 97 & 73.5 \\
Associate professor & 146 & 40.6 & & 214 & 59.4 \\
Assistant professor & 459 & 48.4 & & 490 & 51.6 \\
Assistant & 326 & 54.4 & & 273 & 45.6 \\
Coordinator professor & 71 & 49.0 & & 74 & 51.0 \\
Adjunct professor & 308 & 54.6 & & 256 & 45.4 \\
Professor Equiparado (coordinator/adjunct/assistant) & 188 & 51.2 & & 179 & 48.8 \\
\hline
\end{tabular}


Table 2 Length of contract by sex

\begin{tabular}{lccccc}
\hline & \multicolumn{2}{c}{ Female } & & \multicolumn{2}{c}{ Male } \\
\cline { 2 - 3 } \cline { 5 - 5 } & Count & Row N\% & & Count & Row N\% \\
\hline Validity of the contract & & & & \\
Less than 1 year & 170 & 48.9 & & 178 & 51.1 \\
Between 1 and 3 years & 391 & 50.9 & 377 & 49.1 \\
More than 3 years & 741 & 46.3 & 860 & 53.7 \\
\hline
\end{tabular}

dominant in lower occupational categories such as assistant (female assistants $54.4 \%$; male assistants - 45.6\%).

In private HEIs, whose academic positions are coordinator professor, adjunct professor and professor Equiparado (coordinator/adjunct/assistant), the difference between male and female academics was not as significant as in public HEIs. It has been argued that private HEIs are considered of a lower status compared with public universities (Correia et al., 2002), which can explain the higher representation of women. Another explanation is that because positions in private HEIs are of a lower status and lower paid, men tend to seek jobs in public HEIs or in the higher paid corporate sector and women take their place in the queue (Reskin and Roos, 1990).

Regarding the length of contract by sex (Table 2), more women than men had contracts of between 1 and 3 years (50.9\% and 49.1\%, respectively) and more men than women had contracts of more than 3 years $(53.7 \%$ and $46.3 \%$, respectively). The difference between men and women with contracts of less than 1 year was residual.

Finally, regarding the type of employment by sex, more male than female academics worked part-time (238 female academics and 267 male academics). The explanation is probably that men's work commitments and related employment patterns are often different to those of woman, despite women's labour market participation in numerical terms now being roughly comparable with men's (Munn, 2011). Moreover, more male academics tend to work part-time in HEIs and also parttime outside HEIs where they are better financially rewarded. The difference between men and women with respect to full-time employment is residual.

In private and public universities, there were two significant differences between male and female academics with respect to type of employment. In public universities, there were more male than female academics working full-time (57\% and $43 \%$, respectively), while in private universities there were more female than male academics working part-time $(54.5 \%$ and $45.5 \%$, respectively).

Regarding general satisfaction by sex and academic position, we can see that in the top professional position in universities or polytechnic institutes (full professor and coordinator professor) female academics were more satisfied, whereas at the beginning 
of their professional career female academics were less satisfied. This contrasted with polytechnic institutes where women were slightly happier than men (Table 3).

With respect to general satisfaction by sex and type of employment, both female and male academics working part-time were more satisfied than female and male academics working full-time (Table 4).

Regarding general satisfaction by sex and age groups, the younger group of academics (both men and women) were the most satisfied (Table 5).

Despite some progress, in several aspects of academic careers women still experience segregation and inequality, whereas gender equality should mean that

Table 3 General satisfaction by sex and academic position

\begin{tabular}{lll}
\hline & & Index general satisfaction \\
\cline { 2 - 3 } & & Mean \\
\hline Academic position & & \\
Full professor & Female & 7.20 \\
& Male & 6.93 \\
Associate professor & Female & 6.25 \\
& Male & 6.43 \\
Assistant professor & Female & 6.04 \\
& Male & 6.12 \\
Assistant & Female & 6.67 \\
& Male & 6.83 \\
Coordinator professor & Female & 6.26 \\
Adjunct professor & Male & 5.89 \\
& Female & 6.20 \\
Professor Equiparado (coordinator/adjunct/assistant) & Male & 6.01 \\
No answer & Female & 6.36 \\
& Male & 6.21 \\
& Female & 6.49 \\
\hline
\end{tabular}

Table 4 General satisfaction by sex and type of employment

\begin{tabular}{llc}
\hline & & Index general satisfaction \\
\hline & & Mean \\
\hline Working regime & & \\
Part-time & Female & 6.99 \\
& Male & 7.22 \\
Full-time & Female & 6.20 \\
& Male & 6.14 \\
\hline
\end{tabular}


Table 5 General satisfaction by sex and age groups

\begin{tabular}{lll}
\hline & & Index general satisfaction \\
\hline & & Mean \\
\hline Age & & \\
$\leqslant 30$ years & Female & 7.34 \\
& Male & 7.12 \\
$31-40$ years & Female & 6.45 \\
& Male & 6.34 \\
$41-50$ years & Female & 6.09 \\
& Male & 6.26 \\
$51-60$ years & Female & 6.10 \\
& Male & 6.33 \\
& Female & 6.82 \\
& Male & 6.31 \\
\hline
\end{tabular}

both men and women have the same opportunities to choose an academic career path (Webber and Williams, 2008), without being influenced by negative cultural prejudices or stereotypes. Therefore, segregation is a significant structural obstacle to women achieving equal economic rights and fair choices with respect to professional participation.

\section{Discussion and Conclusion}

This survey has demonstrated that in public HEIs, male academic respondents are dominant in higher academic positions such as full professor and associate professor, while female academics are dominant in lower occupational categories such as assistant and reader. Second, in private HEIs the difference between male and female academics with respect to academic positions is not as significant as in public HEIs. Third, more female academics have contracts of between 1 and 3 years, whereas more male academics have contracts of more than 3 years. This means that male academics have more career stability than female academics. Finally, in public universities there are more male academics than female academics working full-time, but not in public polytechnics. In private universities, we find that there are more female academics than male academics working part-time and full-time.

As previously discussed, an important group contributing to the culture of an institution is the faculty or academic staff. In Portugal, as in other countries, demands for accountability, recent budget cuts, and control and the knowledge economy have led to deteriorating academic working and employment conditions (Santiago and Carvalho, 2008). 
In this context, women still experience difficulties in building academic careers. The literature on gender and academic careers is sparse in the Portuguese context as Carvalho and Santiago (2010, 239) emphasize:

While gender issues are of general concern, less attention is paid to their influence on women entering academic careers. In Portugal, this topic is almost entirely absent from research on higher education, even if it is important for gender equity and for the democratization of the academic profession in Portugal.

This survey of men and women in academia in Portugal has demonstrated the continuing vertical and horizontal segregation of women academics. It has also demonstrated that women are less satisfied with their working lives and the pressures of balancing academic workloads with other responsibilities. It can therefore be concluded that both men and women were satisfied, but not very satisfied with their academic careers. However, gender differences did emerge in relation to advising other people to work in their current and primary institution, where women appeared to be more indecisive than men. This indicates that women may be less self-confident in advising others, possibly due to the fact that they are themselves having a difficult path in building their professional career. High satisfaction rates were indicated by both female and male academics in relation to non-academic staff (administrative staff, technical and laboratory staff), teaching climate and colleagues. This suggests that they enjoy teaching and consider that they have sufficient administrative support to effectively carry out their roles. One important finding was that both female and male academics were less satisfied with research climate and conditions of employment across all sectors in HEIs. With Portuguese HEIs currently facing deteriorating financial support and managerial controls, this may have an impact on the two dimensions in which academics reveal less job satisfaction.

Other gender differences emerged with female academics being more satisfied than male academics with management, colleagues and the institution's prestige, while male academics were more satisfied than female academics with teaching and research climate and with personal and professional development. Despite the expansion of Portuguese higher education which was accompanied by feminization, there are still few women in management positions. It appears from other studies that women dedicate more time than male colleagues to their family and therefore do not develop high expectations concerning management roles (Carvalho and Machado, 2011). This can also explain why women have less time to do research. Moreover, as universities and polytechnics are male dominated, lower satisfaction of women in research and teaching may reflect their difficulty in accessing men's networks (Carvalho et al., 2012). Thus women's lower satisfaction levels with teaching and research climate and with personal and professional development are a clear indicator of how they respond to an organizational context that shapes and reshapes gender identities in HEIs (Ely and Padavic, 2007). 
Significant gender differences emerged in relation to the personal and professional development of academics. Female academics were less satisfied than male academics with all aspects of the dimension 'Personal and Professional Development', but the biggest difference was in relation to satisfaction with conditions for balancing between work and family. This indicates that policymakers in Portuguese HEIs need to consider implementing parental leave policies that will enable women academics to achieve better work/life balance.

Differences in representation between academic women and men in public and private universities and polytechnics in Portugal reflect the relative status of these institutions: the higher the status, the higher the representation of men in senior positions. Conversely, the lower the status, the more likely men will seek employment elsewhere, leaving women to take their place in the job queue (Reskin and Roos, 1990; Hagedorn, 1995).

Therefore, this data needs to be carefully examined by institutional leaders and policymakers in order to promote academic satisfaction because, as Silva (1998) argues, being in the market today requires a permanent evaluation of competitive ability. Competition requires job satisfaction that may create more productive academics and provide impetus for social change. The urgent imperative is to open up new possibilities for women's career aspirations to move beyond traditional stereotypes, relating to work-life balance, the glass ceiling and the culture of HEI workplaces (Hagedorn, 1995; Hughes, 2011; Munn, 2011).

In this context, a set of concrete initiatives aimed at improving the professional conditions of women in academia and the development of equal opportunity policies need to be implemented. For instance, regulations to allow women and men to share parental leave are required, similar to those in Sweden (White, 2011). Other measures might include flexible work arrangements, flexible hours, working from home and also more support for women on maternity leave to transition back to work. Additional measures might be greater availability and acceptance of part-time work for men and women in academia to enable them to combine work and family. Dual careers are now often the norm and universities need to adjust their personnel policies and working conditions to reflect this reality (Dubach et al., 2012).

There have been some improvements in recent years in academic careers in Portuguese higher education. However, unless HEIs address dual careers, flexible working arrangements and part-time work, they will not be able to attract and retain top academics that will increasingly move to institutions — and countries — that provide the working conditions they require.

\section{References}

Ackers, L. (2010) 'Internationalisation and equality: The contribution of short stay mobility to progression in science careers', Recherches Sociologiques et Anthropologiques 40(1): 83-103. 
August, L. and Waltman, J. (2004) 'Culture, climate, and contribution: Career satisfaction among female faculty' Research in Higher Education 45(2): 177-192.

Barrett, L. and Barrett, P. (2011) 'Women and academic workloads: Career slow lane or cul-de-sac?' Higher Education 61(2): 141-155.

Bartosz, K.L., Stevens, P. and Stevens, E. (2006) Women's career decisions in different developmental stages, http://counselingoutfitters.com/Stevens.htm, accessed 13 November 2011.

Bender, K.A. and Heywood, J.S. (2006) 'Job satisfaction of the highly educated: The role of gender, academic tenure and comparison income', Scottish Journal of Political Economy 53(2): 253-279.

Bilimoria, D., Perry, S., Liang, X., Stoller, E., Higgins, P. and Taylor, C. (2006) 'How do female and male faculty members construct job satisfaction? The roles of perceived institutional leadership and mentoring and their mediating processes', The Journal of Technology Transfer 31(3): 355-365.

Bimrose, J. (2001) 'Girls and women: Challenges for career guidance practice', British Journal of Guidance and Counselling 29(1): 79-95.

Bimrose, J. (2004) 'Sexual harassment in the workplace: An ethical dilemma for career guidance?', British Journal of Guidance and Counselling 32(1): 109-123.

Cabrera, E.F. (2009) 'Protean organizations reshaping work and careers to retain female talent' Career Development International 14(2): 186-201.

Carvalho, T. (2012) 'Shaping the 'New' Academic Profession: Tensions and Contradictions in the Professionalization of Academics', in G. Neave and A. Amaral (eds.) Higher Education in Portugal 1974-2009: A Nation, a Generation, Dordrecht: Springer, pp. 329-352.

Carvalho, T. and Machado, M.L. (2011) 'Senior Management in Higher Education', in B. Bagilhole and K. White (eds.) Gender, Power and Management: A Cross-Cultural Analysis of Higher Education, Basingstoke: Palgrave Macmillan, pp. 90-109.

Carvalho, T., Özkanli, Ö. and Machado-Taylor, M.L. (2012) 'Perceptions and attitudes of senior managers toward gender in academia: A comparative study from Portugal and Turkey', Educação, Sociedade \& Culturas 35(35): 45-66.

Carvalho, T. and Santiago, R. (2010) 'New challenges for women seeking an academic career: The hiring process in Portuguese higher education institutions', Journal of Higher Education Policy and Management 32(3): 239-249.

CIREM (2007) Meta-Analysis of Gender and Science Research - Project Methodology, Barcelona: CIREM Foundation.

Commission of the European Communities (1993) Equal Opportunities: Second Positive Action Programme for Female Staff of the Commission (1992-1996), Brussels: European Commission, Directorate-General Human Resources and Security.

Correia, F., Amaral, A. and Magalhães, A. (2002) Diversificação e diversidade dos sistemas de ensino superior: $O$ caso Português, Lisbon: Edição do Conselho Nacional de Educação.

Dubach, P., Graf, I., Stutz, H. and Gardiol, L. (2012) Dual-career couples at Swiss universities. Paper presented to the 7th European Conference on Gender Equality in Higher Education; 29-31 August, Bergen, Norway.

Ely, R. and Padavic, I. (2007) 'A feminist analysis of organisational research on sex differences', Academy of Management Review 32(4): 1121-1143.

European Commission (2006) She Figures 2006, Women and Science, Statistics and Indicators, Brussels: European Commission.

European Commission (2012) She Figures 2012, Women and Science, Statistics and Indicators, Brussels, Belgium: European Commission.

European Union (EU) (2010) Traditional stereotypes remain the biggest challenge for gender equality in education, http://europa.eu/rapid/pressReleasesAction.do?reference=IP/10/695\&format=HTML\& aged $=1 \&$ language $=$ EN\&guiLanguage $=$ en, accessed 13 November 2011.

Eurydice Network (2009) Information on education systems and policies in Europe, http://eacea.ec.europa. eu/education/eurydice/documents/thematic_reports/120EN_HI.pdf, accessed 20 June 2011. 
Gazioglu, S. and Tansel, A. (2006) 'Job satisfaction in Britain: Individual and job related factors', Applied Economics 38(10): 1163-1171.

GPEARI (2010) Docentes do Ensino Superior [2001 a 2008], Lisbon: Gabinete de Planeamento, Estratégia, Avaliação e Relações Internacionais.

Guerreiro, M.D., Lourenço, V. and Pereira, I. (2006) Boas Práticas de Conciliação entre Vida Profissional e Vida Familiar. Manual para as Empresas, Lisbon: CITE - Comissão para a Igualdade no Trabalho e no Emprego.

Hagedorn, L.S. (1995) Wage equity and female faculty job-satisfaction: The role of wage differentials in a job satisfaction causal model. Paper presented at the ASHE Annual Meeting; 2-5 November, Orlando, FL.

Hughes, D. (2011) 'A New Era for Careers - Choices and Consequences', in M. Munn (ed.) Unlocking Potential - Perspectives on Women in Science, Engineering and Technology, London: The Smith Institute, pp. 54-61.

Kuperus, H., Turchetti, C. and Rode, A. (2008) Recruitment and Equal Opportunities Systems in National, European and International Civil Services, Brussels: European Parliament.

Machado-Taylor, M.L., Meira Soares, V., Ferreira, J.B. and Gouveia, O.M.R. (2011) 'What factors of satisfaction and motivation are affecting the development of the academic career in Portuguese higher education institutions?', Revista de Administração Pública 45(1): 33-44.

Machado-Taylor, M.L., Meira Soares, V. and Gouveia, O. (2010) 'The study of academic job satisfaction and motivation: An ongoing study in Portuguese higher education' Global Business \& Economics Anthology II(2): 242-246.

Munn, M. (ed.) (2011) Unlocking Potential - Perspectives on Women in Science, Engineering and Technology, London: The Smith Institute.

OECD (2006) Women in Scientific Careers: Unleashing the Potential, Paris: OECD Publishing.

Okpara, J.O., Squillace, M. and Erondu, E.A. (2005) 'Gender differences and job satisfaction: A study of university teachers in the United States', Women in Management Review 20(3): 177-190.

Oshagbemi, T. (2000) 'Gender differences in the job satisfaction of university teachers', Women in Management Review 15(7): 331-343.

Reskin, B.F. and Bielby, D. (2005) 'A sociological perspective on gender and career outcomes', Journal of Economic Perspectives 19(1): 71-86.

Reskin, B.F. and Roos, P.A. (eds.) (1990) Job Queues, Gender Queues: Explaining Women's Inroads into Male Occupations, Philadelphia: Temple University Press.

Santhapparaj, A.S. and Alam, S.S. (2005) 'Job satisfaction among academic staff in private universities in Malaysia', Journal of Social Sciences 1(2): 72-76.

Santiago, R. and Carvalho, T. (2008) 'Academics in a new work environment: The impact of new public management on work conditions', Higher Education Quarterly 62(3): 204-223.

Silva, R.B. (1998) 'Para uma Análise da Satisfação com o Trabalho', Sociologia, Problemas e Práticas 26(July): 149-178.

Silva, R.B. (2011) Valores e Felicidade no Século XXI: Um Retrato Sociológico dos Portugueses em comparação europeia, p. 240, http://repositorio-iul.iscte.pt/handle/10071/2948, accessed 20 June 2011.

Ssesanga, K. and Garrett, R.M. (2005) 'Job satisfaction of university academics: Perspectives from Uganda', Higher Education 50(1): 33-56.

Stevens, P.A. (2005) The Job Satisfaction of English Academics and Their Intentions to Quit Academe, London: National Institute of Economic and Social Research.

United Nations (2010) The World's Women 2010: Trends and Statistics, New York: United Nations, Department of Economic and Social Affairs.

Ward, M.E. and Sloane, P.J. (2000) 'Non-pecuniary advantages versus pecuniary disadvantages: Job satisfaction among male and female academics in Scottish universities', Scottish Journal of Political Economy 47(3): 273-303. 
Webber, G. and Williams, C. (2008) 'Mothers in 'good' and 'bad' part-time jobs: Different problems, same results', Gender \& Society 22(6): 752-777.

White, K. (2011) 'Legislative Frameworks for EO', in B. Bagilhole and K. White (eds.) Gender, Power and Management: A Cross Cultural Analysis of Higher Education, Basingstoke: Palgrave Macmillan, pp. 20-49.

White, K., Riordan, S., Ozkanli, O. and Neale, J. (2010) 'Cross cultural perspectives of gender and management in universities', South African Journal for Higher Education 24(4): 649-660.

\section{Correction}

Kate White and Odilia Gouveia were not included in the HTML version of this article. Originally published 5 November 2013. These corrections have been made in this final version.

\section{Appendix}

Table A1 Dimensions of satisfaction

Teaching climate

Management of the institution/ department/unit
Colleagues
With the distribution of teaching service for teachers of your department/organizational unit

With the recognition from your peers

With teaching facilities (e.g., classrooms, laboratories, etc.)

With the behaviour of your students in class time

With training of students

With the results of your work as a faculty member

With your degree of autonomy in your teaching practice

With class sizes

With the organization of schedules

With those in top management positions in your institution

With those in top management positions in your department/

organizational unit

With communication with managers

With the management's response to faculty needs

With the ability of those in positions of management to

innovate

With the time that those in management positions take to respond to the needs of faculty

With the skills of faculty of your department/organizational unit

With the scientific quality of the faculty of your department/ organizational unit in comparison with faculty of other similar institutions

With the pedagogic quality of the faculty of your department/

organizational unit in comparison with faculty of other similar institutions

With the interaction between faculty members of different courses

With the cooperation with colleagues from different departments/units

With the openness to change shown by faculty of your department/organizational unit 
Table A1 continued

Non-academic staff (administrative staff, With the cooperation of administrative staff in your institution technical and laboratorial staff ...) With the cooperation of technical-lab staff in your institution With the performance of non-academic staff in your institution With the adequacy of the number of non-academic staff to the

Physical work environment amount of existing work

With the quality of the office

With the adequacy of laboratory equipment to your needs

With the adequacy of computer facilities to your needs

With the adequacy of reviews and books in your institution to carry out your work

With food service (restaurant/bar/canteen)

With the cleanup of the institution

With the equipment available to faculty and their families

(e.g., gym, nursery, living spaces ...)

With the existence of an area to monitor the students

(e.g., ask questions)

With the fact that you have to share the office

With the existence of space/s to hold meetings

With the size of classrooms

Conditions of employment

With the availability of parking for faculty

With your remuneration

With the career opportunities

With job security

Personal and professional development With the conditions you have to balance work and family life With the conditions you have for your personal development

With the conditions you have for your professional

development

Institutions' culture and values

With the academic freedom you have

With the participation of faculty of your institution in

decision-making processes

With the ability to innovate in your institution

Institutions' prestige

With the prestige of your institution

With the international partners of your institution

With the national partners of your institution

With the efforts of your institution to improve its image

Research climate

With the time you have to do research

With the recognition by the institution of your research work

With the financial resources to do research

With the logistical conditions to do research

With your research outputs

With the degree of internationalization of your research work

With the opportunities you have to do research

With your number of publications/presentations

General satisfaction

With your job

With your institution

With the opportunity you have to update knowledge

With the adequacy of your skills to your teaching practice

With the social prestige of your job 